\section{Soaking, Temperature, and Seed Placement Affect Seed Germination and Seedling Emergence of Litchi chinensis}

\author{
Chunyang Zhang, Jiefang Wu, Danwen Fu, Limin Wang, Jiezhen Chen, \\ Changhe Cai, and Liangxi $\mathrm{Ou}^{1}$ \\ Institution of Fruit Tree Research, Guangdong Academy of Agricultural \\ Sciences, Guangzhou City 510640, Guangdong Province, China; and Key \\ Laboratory of South Subtropical Fruit Biology and Genetic Resource \\ Utilization, Ministry of Agriculture, China
}

Additional index words. recalcitrant seed, imbibition, high temperature, seed germination, seed orientation, burial depth, seedling

\begin{abstract}
To find efficient ways to increase the percentage of seed germination and seedling emergence in litchi (Litchi chinensis Sonn.), we investigated the effects of soaking and high temperature on seed germination, as well as the influence of seed placement (orientation and burial depth) on seedling emergence. Seeds of most tested litchi cultivars soaked in water had a better germination performance than seeds without soaking. More than $90 \%$ germination of tested litchi seeds was obtained when the soaking times were 26-54 hours. During presprouting, short-term high temperatures $\left(37-44^{\circ} \mathrm{C}\right)$ exerted a negative effect on seed germination rate, but did not influence the germination percentage. In addition, high temperatures $\left(>42{ }^{\circ} \mathrm{C}\right)$ compromised the further growth of sprouted litchi seeds. Burial depth and seed orientation both significantly influenced the seedling recruitment. There was a reduction in seedling emergence with an increase in burial depth. Seeds at the depth of $2 \mathrm{~cm}$ showed the best seedling emergence with an average percentage of $90 \%$. Litchi seedling emergence was greatest and most rapid when seeds were sown $2 \mathrm{~cm}$ deep, positioned flat, on their sides, and with the radicle oriented downward.
\end{abstract}

Litchi (Litchi chinensis Sonn., Sapindaceae) is an important subtropical fruit tree that originated in China. Due to the delicate flavor, pleasant appearance, and fragrance, it has been known as "one of the top four fruits" along with banana, pineapple and longan in Southern China. In 2010, the cultivated area of litchi in China was about 0.57 million hectares with a total production of 1.7 million tons. The litchi industry has been developed in other countries, including Madagascar, India, South Africa, Thailand, America, Israel, Mauritius, and Mexico (Chen et al., 2013). Litchi is generally propagated by seeds, stem cuttings, grafting, marcottage, and stooling. However, new litchi cultivars with improved and desired characteristics can only be selected from seedlings (Menzel, 1985). The germination performance of seeds and the seed placement in sowing are important to achieve seedlings (Aou-ouad et al., 2014; de Andrade et al., 2004).

Litchi seeds are considered to be "recalcitrant," due to their high sensitivity to

Received for publication 26 Nov. 2014. Accepted for publication $20 \mathrm{Feb} .2015$.

We gratefully thank Meron P. Zalucki and Jacinta Zalucki for significant scientific and linguistic revisions. ${ }^{1}$ To whom reprint requests should be addressed; e-mail gdglxo@126.com. seeds are vulnerable to drying in field, soaking has not yet been applied in practice.

Temperature also affects seed germination. Too high or too low temperatures could decrease seed viability (Corbineau et al., 1986; Eberle et al., 2014). Litchi fruits are mainly harvested in June and July in China when the soil temperature reaches $\approx 40{ }^{\circ} \mathrm{C}$. Seeds of 2-7-6 litchi cultivar incubated at $40^{\circ} \mathrm{C}$ for more than $2 \mathrm{~d}$ exhibited an inhibition in the growth of radicle and plumule. Longterm exposure to $40{ }^{\circ} \mathrm{C}$ for more than $4 \mathrm{~d}$ reduced germination percentage of seeds, and there was a reduction in germination rate with an increase in exposure time ( $\mathrm{Fu}$ et al., 2014b). Fu et al. (2014a) pointed out that the upper limit for seed germination of 'Qiyueshu' litchi was $42{ }^{\circ} \mathrm{C}$. Exposure to temperatures exceeding $42^{\circ} \mathrm{C}$ for $24 \mathrm{~h}$ caused an inhibition in seed germination and seedling emergence. Therefore, temperature may be an important influence factor for germination of litchi seeds.

Seed orientation and sowing depth both play important roles in seed germination and seedling emergence (Aou-ouad et al., 2014; Huang et al., 2007; Thomas, 1978). Recalcitrant seeds of coconut sown in horizontal orientation exhibited much quicker germination and better growth of seedlings (Thomas, 1978). Planting seeds of Balanites aegyptiaca horizontally or vertically with stalk end downward showed better germination (Elfeel, 2012). The seedling emergence was slower when seeds were sown at deeper depth in Rhamnus alaternus and $R$. ludovici-salvatoris (Aou-ouad et al., 2014). Though litchi seeds are all direct-seeded after extraction from the fruits, little research about the seed orientation and sowing depth has been reported in litchi.

Litchi seeds were seldom fully germinated when sown in a humid sand bed under shade or in carbonized rice hull (de Andrade et al., 2004; Prasad et al., 1996). We also observed that the traditional method of planting litchi seeds without any pretreatment resulted in inferior seedling uniformity and less efficiency in the production methods. Therefore, studies are needed to improve litchi seed germination methods. In the present study, we added soaking and presprout steps during seed germination before sowing litchi seeds. Specifically, we investigated the relationship between soaking and seed germination, and determined the appropriate soaking time for seed germination in litchi. Furthermore, we examined the effects of short-term high temperatures on germination of litchi seeds. Finally, the influence of seed orientation and burial depth on litchi seedling recruitment was studied. The objectives of these experiments were to find fast and efficient ways to increase the percentage of seed germination and seedling emergence, which are important for field production.

\section{Materials and Methods} soaking before sowing enables a more rapid imbibition than is usually the case in a nursery bed, resulting in more rapid seed germination (Schmidt, 2000). Though litchi
General. The litchi cultivars used in the experiments were late-maturing types. The 
harvest times for fruits of different cultivars were similar. Fully ripe fruits of different litchi cultivars that had good flavor and were ready to be eaten were harvested from trees grown in Litchi Germplasm Repository, Ministry of Agriculture, in Guangzhou, China. We removed remnants of pulp on the surface of seeds by washing with water. All seeds from different cultivars were plump and had developed normally. The following four experiments were separate, and seeds used in different experiments were from separate seed lots. Seeds were soaked in a plastic drum filled with water and the water was changed daily. Litchi seeds were presprouted on a stainless steel iron plate covered with wet gauze. The gauze was kept moist and the seeds were washed every $2 \mathrm{~d}$ to prevent mildew.

Effects of soaking treatment on seed germination. Fresh seeds of ten litchi cultivars (Shali, Heimiandeng, Huaizhi, Yeshengli, Tongshachihuaizhi, Jinzhong, 2-5-1, Maquechun, Budai, and Baitangli) were tested in this experiment. About 60 seeds of each cultivar were divided equally into two groups. In the control group, seeds of each cultivar were not soaked before presprouted by covering with wet gauze. In the treatment group, seeds were soaked in water for $48 \mathrm{~h}$ and then were presprouted by covering with wet gauze as described in the control group. The emergence of the radicle was regarded as the criterion for seed germination. The number of germinated seeds was counted daily, and final germination percentage of each cultivar was determined after $9 \mathrm{~d}$.

Effects of soaking times on seed germination. Fresh seeds of three litchi cultivars (Budai, Baitangli, and Maquechun) were steeped in water. Thirty seeds were sampled at roughly two hourly intervals for a maximum soaking time of $60 \mathrm{~h}$. This means that seeds were pregerminated after being soaked in water for $2,4,6,8,10,12,14,16,24,26,28,30,32,34$, $36,38,40,48,50,52,54,56,58$, or $60 \mathrm{~h}$, respectively. The sampled seeds were pregerminated by covering with wet gauze. The number of germinated seeds was counted after $12 \mathrm{~h}$ and then daily. The germination percentage was determined when seeds in all soak treatments were fully germinated in each cultivar.

Short-term high temperature treatments in seed germination. We set a series of different temperatures to test the effects of short-term high temperature on germination of litchi seeds. There were 50 seeds in each treatment. Seeds of 'Cuiye' and 'Seedling0795' were soaked in water for $48 \mathrm{~h}$, removed from the water and presprouted at 37,38 , $39,40,41,42,43$, or $44^{\circ} \mathrm{C}$ by covering with wet gauze in constant temperature incubator for $24 \mathrm{~h}$, respectively. Subsequently, they were placed indoors to continue to grow, where the mean midday temperature was $33 \pm$ $2{ }^{\circ} \mathrm{C}$, and mean night temperature was $27 \pm$ $2{ }^{\circ} \mathrm{C}$. The control group was not subjected to high temperatures after soaking but was directly germinated indoors under the same temperature regime as the treatment groups above. The count of germinated seeds was made daily after the treated seeds were placed indoors. This experiment was run for a total of $14 \mathrm{~d}$. Germination percentage and germination rate were calculated. Germination rate was expressed as the percentage of seeds germinated within $2 \mathrm{~d}$ after presprouting in indoor conditions. We chose $2 \mathrm{~d}$ because most seeds of two litchi cultivars had germinated $(>80 \%)$ within $2 \mathrm{~d}$ under controlled conditions.

Sowing seeds at different seed orientations and depths. Seeds of 'Zengchenggualv' litchi were soaked in water for $48 \mathrm{~h}$ and were presprouted in indoor conditions. After the emergence of radicle, seeds were sown in four orientations (seed laid flat, seed laid on its side, seed laid vertically with the radicle upward, and seed laid vertically with the radicle downward). Seeds sown in each of the four orientations were placed in soil at three different depths of 2,4 , or $6 \mathrm{~cm}$. Three replicates were used for each treatment and 10 seeds were sown in each replicate. A randomized block design was used in the experiment. Some seedlings began to emerge at the surface of soil on day 7, and the final percentage of seedling emergence was determined two weeks after sowing.

Data analyses. The data of seed germination and seedling emergence were statistically analyzed using SPSS 13.0 Statistical Software. Pearson chi-square test and continuity correction were used to examine the significance of differences in germination percentage between seeds soaked in water and those without the soaking treatment. Pearson correlation tests were used to determine the correlations of soaking time with germination percentage, and high temperatures with percentage and rate of germination. General linear model was used to test the effect of seed orientation and burial depth on seedling emergence. ANOVA was used to test the differences in seedling emergence.

\section{Results}

Necessity of soaking seeds in seed germination. Fresh seeds from ten litchi cultivars soaked in water significantly differed in germination percentage from seeds without the soaking treatment ('Tongshachihuaizhi', $P<$ 0.001; 'Jinzhong', $P<0.001$; 'Shali', $P=$ 0.001; 'Heimiandeng', $P=0.001$; 'Huaizhi', $P<0.001$; 'Maquechun', $P=0.006$; 'Baitangli', $P<0.001$; 'Budai', $P=0.008$; '2-5-1', $P<$ 0.001 ; Pearson chi-square test or continuity correction; Fig. 1). Seeds of almost all tested litchi cultivars soaked in water showed better germination performance than those without soaking, and seeds of most litchi cultivars soaked in water fully germinated. Seeds of 'Yeshengli' litchi soaked in water showed a slightly higher germination percentage than seeds without the soaking treatment, but the difference in germination was not significant $(P=0.184$, continuity correction; Fig. 1). Seeds that were not pretreated with soaking germinated slowly with a germination percentage ranging from $29 \%$ to $75 \%$.

Optimal soaking time in seed germination. There was a significant positive correlation between soaking time and germination percentage of seeds from Budai, Baitangli, and Maquechun litchi cultivars $(P<0.001$, Pearson correlation test; Fig. 2).

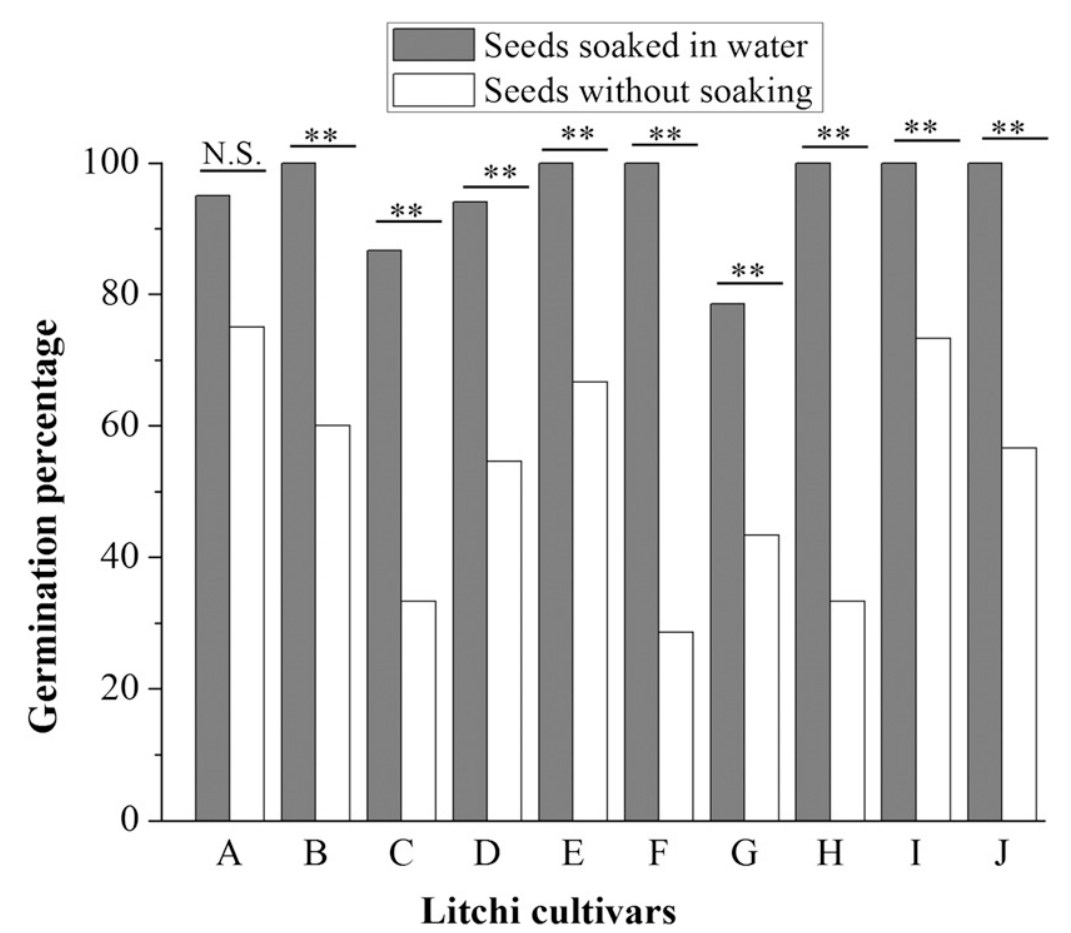

Fig. 1. Effect of soaking on germination of seeds from ten litchi cultivars: A, Yeshengli; B, Tongshachihuaizhi; C, Jinzhong; D, Shali; E, Heimiandeng; F, Huaizhi; G, Maquechun; H, Baitangli; I, Budai; J, 2-5-1. NS $=$ difference is not significant; $* *=$ difference is significant at the 0.01 level. 
We found an increase in germination percentage occurred with extension in soaking time in three litchi cultivars. When seeds of 'Budai' litchi were soaked in water for $2 \mathrm{~h}$, only $17 \%$ germinated, but after soaking for $26 \mathrm{~h}, 90 \%$ germination was obtained. Seeds had fully germinated after soaking for $54 \mathrm{~h}$. Similarly, seeds of 'Baitangli' exhibited 27\% germination after soaking for $2 \mathrm{~h}$, but showed more than $90 \%$ germination after soaking for $16 \mathrm{~h}$ and $100 \%$ germination after soaking for $26 \mathrm{~h}$ in water. Seeds of 'Maquechun' litchi showed $50 \%$ germination after soaking for $2 \mathrm{~h}$, and exhibited $90 \%$ germination after soaking for $8 \mathrm{~h}$, and fully germinated when soaked for $36 \mathrm{~h}$ (Fig. 2).

Effects of short-term high temperatures on seed germination. Seeds of 'Cuiye' and 'Seedling0795' were nearly $100 \%$ germinated when subjected to $37-44{ }^{\circ} \mathrm{C}$ for $24 \mathrm{~h}$ in the process of germination (Fig. 3). No correlations were found between high temperature and germination percentage ('Cuiye', $P=0.547$; 'Seedling0795', $P=0.797$; Pearson correlation test). However, short-term exposure to high temperatures affected the germination rate of litchi seeds. High temperature and germination rate of 'Cuiye' and 'Seedling 0795 ' seeds were negatively correlated ('Cuiye', $P<0.001$; 'Seedling0795', $P=$ 0.048; Pearson correlation test; Fig. 3). The germination rate of 'Cuiye' seeds declined from $92 \%$ at $37{ }^{\circ} \mathrm{C}$ to $38 \%$ at $44{ }^{\circ} \mathrm{C}$, and the germination rate of 'Seedling0795' seeds declined from $60 \%$ at $37{ }^{\circ} \mathrm{C}$ to $32 \%$ at $44{ }^{\circ} \mathrm{C}$, suggesting that litchi seeds subjected to short-term high temperatures germinated slowly. Seeds of the control treatment pregerminated indoors showed high germination percentage and high germination rate. Furthermore, short-term high temperatures above $42{ }^{\circ} \mathrm{C}$ influenced the growth of sprouted seeds in 'Cuiye' and 'Seedling0795' litchi. These sprouted seeds grew slowly and even stopped within 3-4 d after the radicle emerged, but then resumed normal growth.

Effects of different seed orientations and burial depths on seedling emergence. There was no significant interaction effect between seed orientation and burial depth on seedling emergence $\left(\mathrm{GLM}, \mathrm{F}_{6,24}=0.594, P=0.732\right)$. However, the orientation and burial depth both significantly influenced seedling recruitment in litchi (GLM, $\mathrm{F}_{3,24}=7.362, P=0.001$; $\left.\mathrm{F}_{2,24}=85.232, P<0.001\right)$. There was a significant reduction in seedling emergence with an increase in burial depth (ANOVA: $\mathrm{F}_{2,33}=56.647, P<0.001$; Fig. 4). Seeds sown at $2 \mathrm{~cm}$ depth showed the highest seedling emergence with an average percentage of $90 \%$. No significant difference was found among seed orientations of seeds laid-flat, laid on one side and laid vertically with the radicle downward in seedling emergence at the burial depth of $2 \mathrm{~cm}(P>0.05)$. However, there were significant differences among seeds laid vertically with the radicle upward and the other three seed orientations in seedling emergence at the burial depth of $2 \mathrm{~cm}$ (LSD: lay-flat and radicle upward, $P=0.002$; laid on its said and radicle upward, $P=0.008$;

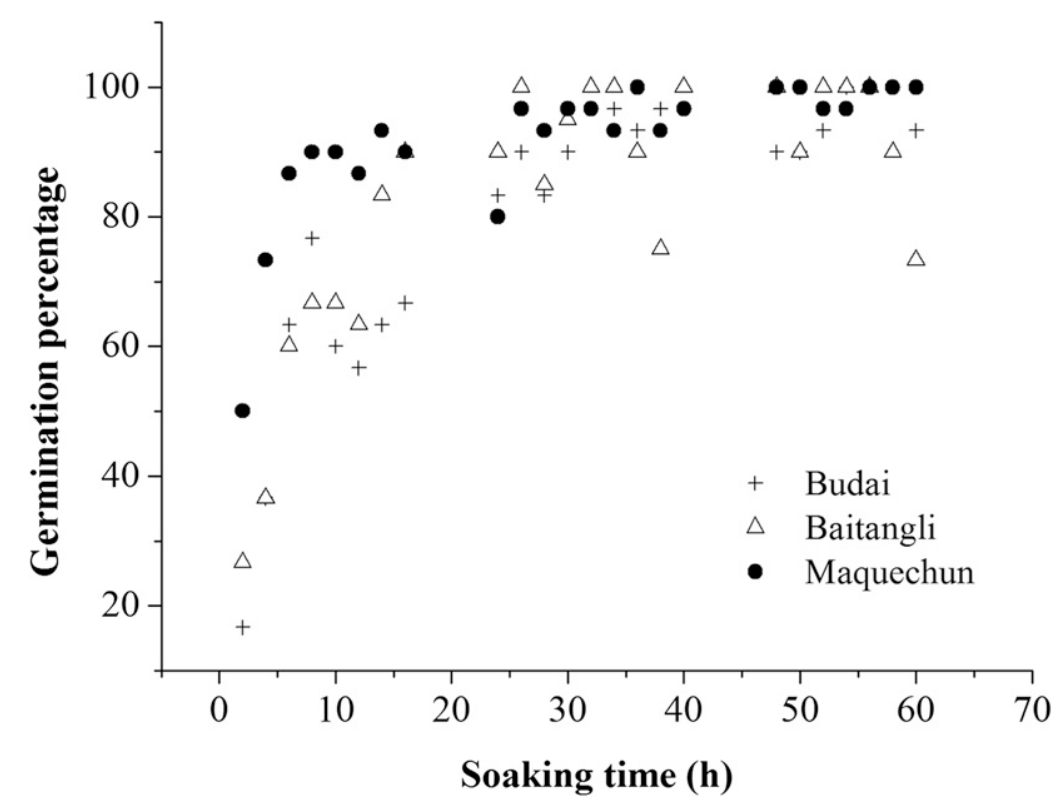

Fig. 2. Germination percentage of seeds from three litchi cultivars under different soaking time treatments.

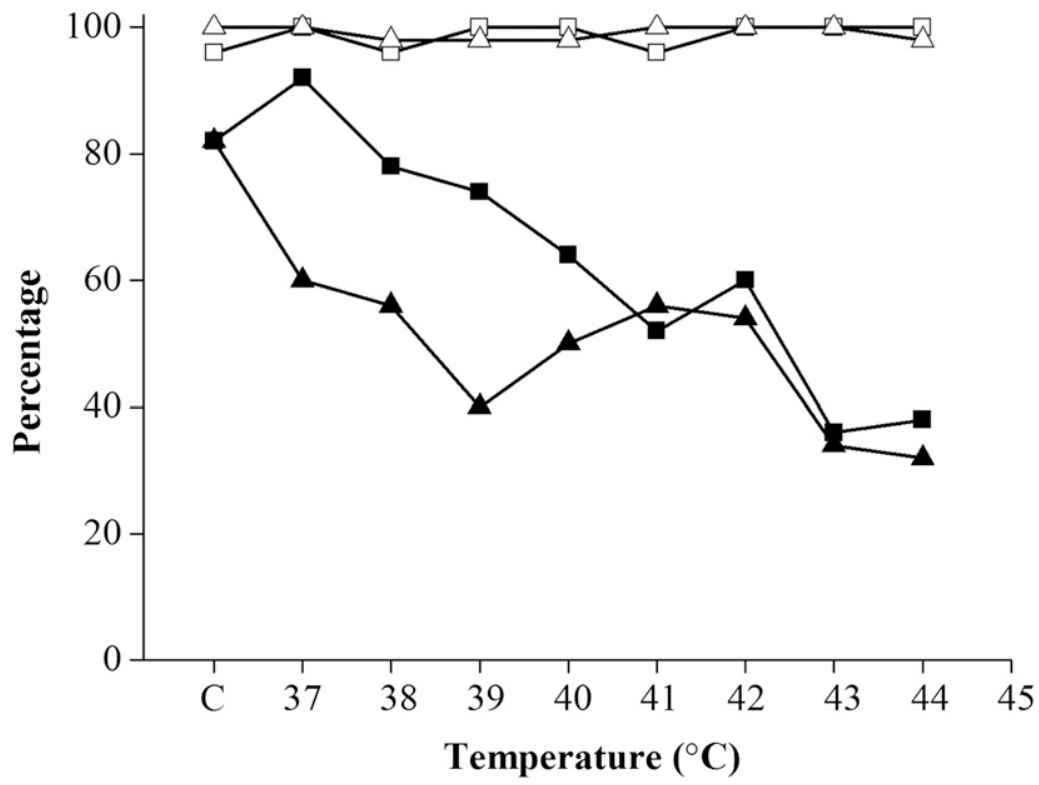

Fig. 3. Germination behavior of litchi seeds from 'Cuiye' and 'Seedling0795' under different high temperature treatments for $24 \mathrm{~h}$. C was the control treatment, in indoor conditions, where the mean midday temperature was $33 \pm 2{ }^{\circ} \mathrm{C}$, and mean night temperature was $27 \pm 2{ }^{\circ} \mathrm{C}$. The square symbol represents 'Cuiye' and the triangle represents 'Seedling0795'. The open symbol indicates germination percentage and the close symbol indicates germination rate.

radicle downward and radicle upward, $P=$ 0.004). The seedling emergence was lower and slower when seeds were sown radicle upward at the sowing depth of $2 \mathrm{~cm}$ (Fig. 4).

\section{Discussion}

Importance of soaking in seed germination. The technique of soaking seeds before sowing is often used in agricultural practices, such as in pitaya, coconut, guava, and Magonia pubescens (Sapindaceae). Seeds imbibe water and trigger a chain of reactions resulting in seedlings (Bhanuprakash et al., 2008; de Macedo et al., 2009; Thomas, 1973;
Zhao et al., 2005). Soaking seeds in water helps reduce the time required for germination, and improve germination percentage (Hartmann and Kester, 1979). However, soaking seeds has not been used in germination of litchi seeds although they are sensitive to desiccation. Our results showed that seeds of almost all tested litchi cultivars soaked in water had higher germination percentage than those without the soaking treatment, and seeds of most litchi cultivars steeped in water were fully germinated. However, there was no significant difference between the soaked seeds of the litchi cultivar Yeshengli and seeds without soaking. The imbibition 


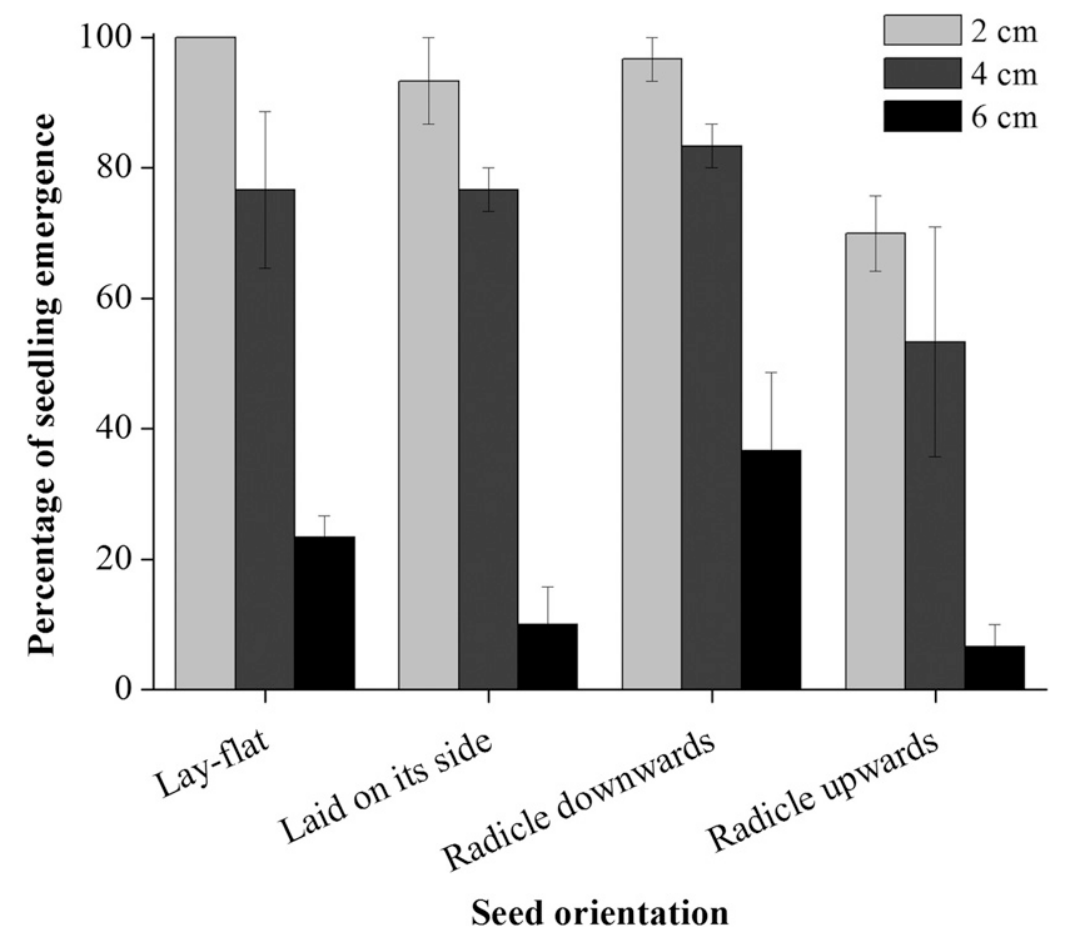

Fig. 4. Percentage of seedlings emergence (mean $\pm \mathrm{SE}$ ) at different seed orientations and different burial depths in litchi.

process both occurred when seeds were submersed in water and when they were sown immediately in humid sand, but soaking enabled a quicker imbibition and might be of benefit for rapid seed germination (Schmidt, 2000).

Soaking time in seed germination. We found that soaking time significantly affected seed germination of litchi. An increase in germination percentage occurred with an extension in soaking time when litchi seeds were soaked in water for 2-60 h. Although the optimal soaking times were different among litchi cultivars, 26-54 h soaking resulted in $90 \%$ to $100 \%$ germination for most litchi cultivars. This phenomenon, that soaking time affects seed germination, has been found in other fruit crops. In pitaya, the optimal soaking times for seeds were $4-6 \mathrm{~h}$, and there was a reduction in germination percentage and germination rate with an increase in soaking time (Zhao et al., 2005). Soaking seeds of guava in distilled water for $48 \mathrm{~h}$ significantly increased the germination percentage, compared with the soaking period of $24 \mathrm{~h}$ (Bhanuprakash et al., 2008). Soaking the recalcitrant seeds of coconut in water for two weeks resulted in higher germination percentage and better growth of seedlings than soaking in water for one week (Thomas, 1973). It appears that the optimal soaking times for different species of fruit tree seeds were quite different. In addition, Woodstock (1988) reported that prolonged soaking might cause anoxia resulting in accumulation of toxic chemicals, and leaching of cellular constituents that might stimulate fungal or bacterial attack. Indeed, we observed that the water was gradually turned turbid and brown with extension in soaking time more than one day. Thus, we suggest that the water should be renewed daily when litchi seeds are soaked in water.

Effects of short-term high temperatures during presprout stage on seed germination. Fu et al. (2014a) found that when seeds of the litchi cultivar Qiyueshu were subjected to $40-52{ }^{\circ} \mathrm{C}$ for $24 \mathrm{~h}$, temperatures above $42{ }^{\circ} \mathrm{C}$ delayed the seedling emergence time after the radicle emerged, temperatures above $44{ }^{\circ} \mathrm{C}$ caused reduction in seed viability, and temperatures above $46{ }^{\circ} \mathrm{C}$ reduced germination percentage and germination rate. In the present study, short-term exposure to high temperatures of $37-44{ }^{\circ} \mathrm{C}$ did not affect the germination percentage. The seeds of 'Cuiye' and 'Seedling0795' under temperatures above $42{ }^{\circ} \mathrm{C}$ treatments for $24 \mathrm{~h}$ exhibited a period of poor growth after the radicle emerged, which was consistent with the conclusion of $\mathrm{Fu}$ et al. (2014a). Temperatures exceeding $37{ }^{\circ} \mathrm{C}$ reduced germination rate of the seeds in the present study, but $\mathrm{Fu}$ et al. (2014a) observed that high temperatures above $46^{\circ} \mathrm{C}$ would reduce the germination rate of litchi seeds. The difference between them may be caused by different cultivars used. The seeds of 'Qiyueshu' had resistance ability to certain high temperature stress as pointed out by $\mathrm{Fu}$ et al. (2014a), but the seeds of 'Cuiye' and 'Seedling0795' may be more vulnerable to high temperatures. The seeds of 'Cuiye' and 'Seedling0795' exposed to high temperatures above $42{ }^{\circ} \mathrm{C}$ for $24 \mathrm{~h}$ grew slowly within 3-4 d after germination, but soon recovered normal growth. We speculate that there may be a slow recovery phase for litchi seeds after suffering the nonlethal high temperatures. Therefore, germination percentage of litchi seeds may not be influenced greatly after sowing in the field when they are subjected to high temperatures for a short time at noon, and we suggest that litchi seeds should better be sown in the field when forecasted soil temperature is below $37^{\circ} \mathrm{C}$ during seed germination.

Effects of seed orientation and burial depth on seedling emergence. The seedling emergence behavior at different depths has never been studied in litchi. Our results showed that the burial depth of seeds significantly influenced the seedling recruitment in litchi. There was a significant reduction in seedling emergence of litchi with depths below $2 \mathrm{~cm}$. Planting seeds at deeper depths probably resulted in more consumption of the carbohydrate reserves during the process of germination and seedling emergence (Huang et al., 2007).

The seedling emergence behavior at different seed orientations has never been studied in litchi. The seed orientation significantly influenced the seedling recruitment in litchi. The seedling emergence was higher and quicker when seeds were placed flat, on their sides and radicle downward than those planted radicle upward at the burial depth of $2 \mathrm{~cm}$. Therefore, growers should ensure seed placement avoids a vertical seed orientation with the radicle upward.

All litchi seeds used in our experiments were plump with normal embryo development. But in some other excellent litchi cultivars with desired characteristics that tended to be inherited by female parent, have some seeds that develop abnormally with partially abortive embryos and also vary in size according to the degree of abortion ( $\mathrm{Lu}$ et al., 2001). These seeds that exhibit a slightly shriveled appearance cannot germinate easily, and the seedlings that do emerge exhibit inferior growth. Further studies on these types of seeds could provide more choices for parent selection and increase the probability of better offspring in artificial cross breeding of litchi.

In the present study, we improved the seed germination method in litchi by adding soaking and presprout steps before sowing in the soil, and explored various sowing methods. Soaking increased seed germination percentage, and $90 \%$ to $100 \%$ germination could be obtained with soaking for 26-54 h. Temperatures above $37^{\circ} \mathrm{C}$ reduced the germination rate. Placing seeds flat and on their sides, orienting the radicle downward, and covering with $2 \mathrm{~cm}$ of medium exhibited the best seedling emergence.

\section{Literature Cited}

Aou-ouad, H.E., H. Medrano, A. Lamarti, and J. Gulías. 2014. Seed germination at different temperatures and seedling emergence at different depths of Rhamnus spp. Cent. Eur. J. Biol. 9:569-578.

Bewley, J.D. and M. Black. 1982. Physiology and biochemistry of seeds in relation to germination. Springer-Verlag, Berlin.

Bhanuprakash, K., H.S. Yogeesha, C. Vasugi, M.N. Arun, and L.B. Naik. 2008. Effect of presoaking treatments and temperature on seed germination of guava (Psidium guajava L.). Seed Sci. Technol. 36:792-794. 
Chen, H.B., L.J. Zhuang, X.M. Huang, and Z.X. Su. 2013. Present situation and development prospect for litchi and longan industry. China Tropical Agriculture 2:12-18. (In Chinese).

Corbineau, F., M. Kanté, and D. Côme. 1986. Seed germination and seedling development in the mango (Mangifera indica L.). Tree Physiol. 1:151-160.

de Andrade, R.A., A.B.G. Martins, and I.V.M. Oliveira. 2004. Influence of the substrate in germination of lychee seeds. Rev. Bras. Frutic. 26:375-376.

de Macedo, M.C., S.P.Q. Scalon, A.P. Sari, H. Scalon Filho, Y.B.C.J. Rosa, and A.D. Robaina. 2009. Biometry of fruit and seeds and germination of Magonia pubescens ST.Hil (Sapindaceae). Rev. Bras. Sementes 31:202-211.

Eberle, C.A., F. Forcella, R. Gesch, D. Peterson, and J. Eklund. 2014. Seed germination of calendula in response to temperature. Ind. Crops Prod. 52:199-204.

Elfeel, A.A. 2012. Effect of seed pre-treatment and sowing orientation on germination of Balanites aegyptiaca (L.) Del. seeds. Am-Euras. J. Agr. and Environ. Sci. 12:897-900.

Fu, D.W., L.M. Wang, L.X. Ou, J.Z. Chen, C.H. Cai, and C.Y. Zhang. 2014a. Effect of high temperature on seed vigor of Litchi. Guangdong Agr. Sci. 5:89-91. (In Chinese).

Fu, D.W., J.F. Wu, L.M. Wang, J.Z. Chen, C.H Cai, C.Y. Zhang, and L.X. Ou. 2014b. Effect of high-temperature germination time on litchi seed vigor. Guangdong Agr. Sci. 16:33-36. (In Chinese).

Harb, A.M. 2013. Reserve mobilization, total sugars and proteins in germinating seeds of durum wheat (Triticum durum Desf.) under water deficit after short period of imbibition. Jordan J. Biol. Sci. 6:67-72.

Hartmann, H.T. and D.E. Kester. 1979. Plant propagation: Principles and practices. 4th ed. Prentice Hall, New Delhi.

Huang, S.Q., G.X. Liu, and J.G. Han. 2007. Effect of seed mass and sowing depth on seedling establishment. Pratacultural Sci. 24:44-49. (In Chinese).

Lu, L.X., H.B. Huang, and C. Menzel (ed.). 2001. A review of embryo development in litchi. Acta Hort. 558:241-242.

Menzel, C.M. 1985. Propagation of lychee: A review. Sci. Hort. 25:31-48.

Prasad, J.S., R. Kumar, M. Mishra, R. Kumar, A.K. Singh, and U.S. Prasad. 1996. Characteristics of litchi seed germination. HorScience 31:11871189.
Ray, P.K. and S.B. Sharma. 1987. Growth, maturity, germination and storage of litchi seeds. Sci. Hort. 33:213-221.

Roberts, E.H. 1973. Predicting the storage life of seeds. Seed Sci. Technol. 1:499-514.

Schmidt, L.H. 2000. Guide to handling of tropical and subtropical forest seed. Danida For. Seed Ctr., Humlebaek, DK.

Thomas, K.M. 1973. Influence of certain physical and chemical treatments on the germination and subsequent growth of coconut Cocos nucifera L. seedlings. a preliminary study. Ceylon Cocon. Q. 24:85-90.

Thomas, K.M. 1978. Influence of seed size and planting orientation on the germination and growth of coconut seedlings in the nursery. Indian J. Agr. Sci. 48:63-67.

Woodstock, L.W. 1988. Seed imbibition: A critical period for successful germination. J. Seed Technol. 12:1-15.

Xia, Q.H., R.Z. Chen, and J.R. Fu. 1990. Physiological changes of litchi seeds before 10 days of maturity. Plant Physiol. Commun. 3:37-38. (In Chinese).

Zhao, C.X., X.Y. Wang, H.B. Li, and F. He. 2005. Preliminary study on germination characteristics of Hylocereus undatus seed. Seed 24: 37-40. (In Chinese). 